\title{
Yeast Translation Elongation Factor eIF5A Expression Is Regulated by Nutrient Availability through Different Signalling Pathways
}

\author{
Marina Barba-Aliaga 1,2®, Carlos Villarroel-Vicente 1,2®, Alice Stanciu 1,2 , Alba Corman 1,2, \\ María Teresa Martínez-Pastor ${ }^{2}$ and Paula Alepuz ${ }^{1,2, * \text { (D) }}$ \\ 1 Instituto Biotecmed, Facultad de Ciencias Biológicas, Universitat de València, C/Dr. Moliner 50, \\ E46100 Burjassot, Spain; Marina.Barba@uv.es (M.B.-A.); carvivi@alumni.uv.es (C.V.-V.); \\ stanciu@alumni.uv.es (A.S.); alba.corman@ki.se (A.C.) \\ 2 Departamento de Bioquímica y Biología Molecular, Facultad de Ciencias Biológicas, Universitat de València, \\ C/Dr. Moliner 50, E46100 Burjassot, Spain; maria.teresa.martinez@uv.es \\ * Correspondence: paula.alepuz@uv.es; Tel.: +34-963-543-462
}

check for

updates

Citation: Barba-Aliaga, M.;

Villarroel-Vicente, C.; Stanciu, A.;

Corman, A.; Martínez-Pastor, M.T.;

Alepuz, P. Yeast Translation

Elongation Factor eIF5A Expression Is Regulated by Nutrient Availability through Different Signalling

Pathways. Int. J. Mol. Sci. 2021, 22, 219. https://doi.org/10.3390/ijms 22010219

Received: 13 November 2020

Accepted: 24 December 2020

Published: 28 December 2020

Publisher's Note: MDPI stays neutral with regard to jurisdictional claims in published maps and institutional affiliations.

Copyright: (C) 2020 by the authors. Licensee MDPI, Basel, Switzerland. This article is an open access article distributed under the terms and conditions of the Creative Commons Attribution (CC BY) license (https: / / creativecommons.org/ licenses/by/4.0/).

\begin{abstract}
Translation elongation factor eIF5A binds to ribosomes to promote peptide bonds between problematic amino acids for the reaction like prolines. eIF5A is highly conserved and essential in eukaryotes, which usually contain two similar but differentially expressed paralogue genes. The human eIF5A-1 isoform is abundant and implicated in some cancer types; the eIF5A-2 isoform is absent in most cells but becomes overexpressed in many metastatic cancers. Several reports have connected eIF5A and mitochondria because it co-purifies with the organelle or its inhibition reduces respiration and mitochondrial enzyme levels. However, the mechanisms of eIF5A mitochondrial function, and whether eIF5A expression is regulated by the mitochondrial metabolism, are unknown. We analysed the expression of yeast eIF5A isoforms Tif51A and Tif51B under several metabolic conditions and in mutants. The depletion of Tif51A, but not Tif51B, compromised yeast growth under respiration and reduced oxygen consumption. Tif51A expression followed dual positive regulation: by high glucose through TORC1 signalling, like other translation factors, to promote growth and by low glucose or non-fermentative carbon sources through Snf1 and heme-dependent transcription factor Hap1 to promote respiration. Upon iron depletion, Tif51A was down-regulated and Tif51B up-regulated. Both were Hap1-dependent. Our results demonstrate eIF5A expression regulation by cellular metabolic status.
\end{abstract}

Keywords: eIF5A; mitochondrial respiration; gene expression; Hap1; heme; TOR; Snf1; iron

\section{Introduction}

Translation factor eIF5A is a small protein that is essential and highly conserved across eukaryotes, and with orthologues in prokaryotes and archaea. Interestingly, eIF5A is the only known protein to contain the amino acid hypusine, which is formed by the addition of a 4-aminobutyl group from polyamine spermidine to a specific conserved lysine residue. Posttranslational eIF5A hypusination occurs in two enzymatic steps: catalysed by deoxyhypusine synthase (DHPS) and deoxyhypusine hydroxylase (DOHH). DHPS and $\mathrm{DOHH}$ are also highly conserved and essential in most eukaryotes but are dedicated to modifying only one protein, which highlights the vital role of hypusinated eIF5A [1]. Though it was initially classified as a translation initiation factor, later studies revealed that eIF5A acts as an elongation factor that binds ribosomes at the E-site to project the hypusinecontaining domain towards the P-site to promote the formation of peptide bonds between amino acid residues that are bad acceptors/donors for the reaction. The polypeptide motifs requiring eIF5A for their synthesis include stretches of consecutive prolines but also combinations of proline, glycine and charged amino acids ([2-6] and is reviewed in [7]). 
Most eukaryotes, including human and yeast, have two genes that encode two extremely similar isoforms of eIF5A. Human genes EIF5A-1 and EIF5A-2 share $84 \%$ of amino acid sequence identity between the corresponding eIF5A encoded isoforms; yeasts TIF51A and TIF51B encode isoforms with 90\% identity. Yeast and human eIF5A proteins also share more than $60 \%$ amino acid sequence identity and are functional homologues as heterologous human eIF5A expression allows yeast to grow with the deletion of eIF5A genes [8-11]. Despite producing very similar eIF5A proteins, the expression of eIF5A paralogue genes is dissimilar. In humans, only the eIF5A-1 isoform is abundant in most cell types, whereas eIF5A-2 expression is limited to the testis and brain [12]. However, both isoforms have been linked with different diseases in which they appear to be overexpressed. eIF5A-1 has been implicated in diabetes, several cancer types, viral infections and neurological diseases. On the contrary, eIF5A-2 is highly expressed in many cancers and its overexpression in certain cell types causes cellular transformation, for which it has been proposed to act as an oncogene [13-16].

In yeast, the genes encoding eIF5A isoforms TIF51A (also known as HYP2) and TIF51B (also known as $A N B 1$ and $H Y P 1$ ) are differentially expressed and reciprocally regulated by oxygen. Under aerobic conditions, TIF51A is highly and TIF51B is poorly expressed. TIF51 $A$ is essential, but TIF51B deletion has no effect on growth. On the contrary, TIF51B is up-regulated and TIF51A down-regulated when oxygen is lacking. TIF51B repression under aerobic conditions is triggered, similarly to other yeast genes induced by hypoxia, via the synergic action of DNA-binding proteins Rox1 and Mot3 through mechanisms that partially depend on the general repressor complex Ssn6/Tup1 [17-20]. The activation of repressor Rox1 in the presence of oxygen is produced via increased levels of heme groups, which are synthesised in mitochondria and serve as a secondary signal for oxygen. Then heme binds and activates nuclear transcriptional factor Hap1, which permits Hap1 to bind and promote the transcription of Rox 1 and many genes required for oxygen utilisation and to control oxidative damage [21]. Conversely, in the absence of heme/oxygen, Hap1 becomes a repressor down-regulating ROX1 and triggering the induction of TIF51B [22]. Unlike the known regulation of TIF51B by oxygen, knowledge about TIF51A regulation is scarce. It is supposed to be constitutively expressed under oxygen conditions, and TIF51A has been suggested to be positively regulated by Hap1 [17]. Additionally, the mechanism of TIF51A repression under anaerobiosis remains unknown.

Despite the two genes encoding eIF5A in both humans and yeast having clearly differential expression patterns, no evidence for a different molecular functionality of isoforms has been found. Indeed, in yeast cells, the expression of either eIF5A paralogue gene from a heterologous promoter restores yeast growth with the deletion of the TIF51A gene in rich media under aerobiosis conditions $[8,10,11,23]$. However, the differential expression of yeast TIF51A and TIF51B genes still suggests a functional specialisation of each eIF5A isoform, in which TIF51A would favour the metabolic adaptation to the presence of oxygen.

In the last few years, several reports have pointed out a function of eIF5A in the regulation of mitochondrial activity. Firstly, studies in mammals have reported the copurification or localization of eIF5A with mitochondria [24,25]. Interestingly, the existence of an alternative human low expressed eIF5A-1 isoform, with an additional N-terminal extension containing a putative mitochondrial targeting sequence, has also been described. When overexpressed, this longer isoform co-purifies with mitochondria [26]. Secondly, there is evidence for the role of eIF5A in preserving mitochondrial morphology, distribution and integrity, obtained in Schizosaccharomyces pombe and mammals [27,28]. Thirdly, the connection between eIF5A and mitochondria-mediated apoptosis has been described, where eIF5A overexpression in human cells increased reactive oxygen species (ROS) and yielded loss of the mitochondrial transmembrane potential, and the release of cytochrome-c and caspase activation $[29,30]$. Fourthly, several reports in mammals have linked eIF5A with both cellular metabolism and respiration. In these studies, the inhibition of hypusinated eIF5A seems to reduce mitochondrial respiration, while leaving glycolytic ATP synthesis 
operative, which improves ischaemic conditions and organ transplantation [31-33]. Finally, and importantly, a recent report describes the modulation of mitochondrial respiration by eIF5A during macrophage activation [34]. Inhibiting the polyamine synthesis pathway and the hypusination of eIF5A blocks mitochondrial oxidative phosphorylation (OXPHOS). Moreover, hypusinated eIF5A is necessary to maintain the tricarboxylic acid (TCA) cycle and the electronic transport chain (ETC) integrity in macrophages by promoting the efficient translation of some mitochondrial enzymes with specific mitochondrial targeting sequences. Hypusinated eIF5A levels are modulated in response to immune stimuli, which suggests that hypusinated eIF5A activity is most critical in cells with increased respiration [34]. Briefly, increasing evidence links eIF5A and mitochondrial function, but whether the effect is direct or indirect, how eIF5A may affect the expression of mitochondrial proteins, and whether eIF5A expression is regulated by mitochondrial metabolism, and how, are questions that still have no answer.

Yeast cells are a feasible eukaryotic model to study the regulation of mitochondrial respiration as yeasts can grow aerobically or anaerobically, and the involved signalling pathways are well-known. In the presence of glucose and oxygen, yeast cells prefer fermentation to respiration because the former can proceed at much higher rates and allows more competitive growth and survival. Nevertheless, glucose fermentation to ethanol is energetically less efficient than aerobic respiration. Thus, under glucose and oxygen conditions, glycolysis and fermentation genes are induced, and key mitochondrial enzymes of the TCA cycle, ETC and OXPHOS, are subjected to glucose repression, as are other genes involved in the utilisation of other alternative carbon sources [35-37]. As yeast cultures in glucose media progress, sugar becomes limiting and yeast cells start metabolising the ethanol produced during fermentation by switching to aerobic respiration, which slows down growth. The transition from fermentation to respiration during this diauxic shift is produced by the up-regulation of TCA cycle, ETC and OXPHOS genes. This gene expression reprogramming involves different signalling pathways, such as protein kinase A (PKA), the target of rapamycin complex I (TORC1), Sch9, Snf1 and Mec1/Rad53, and requires several transcription factors, including Hap1, Hap2/3/4/5, Cat8 and Rgt1/3, as well as communication between the nuclear and mitochondrial genome, and crosstalk between pathways [35-41].

Under high glucose conditions, glucose repression is executed mainly by transcription factor Mig1, together with the Ssn6/Tup1 complex. Snf1, the yeast homologous to mammalian AMP-activated kinase, is the master kinase that removes glucose repression. Snf1 is inhibited by glucose and stimulated when glucose is limiting. Activated Snf1 inhibits Mig1-mediated repression by its phosphorylation and subsequent translocation to the cytoplasm [35-37,42]. High glucose maintains the PKA and TORC1 signalling pathways active and promotes proliferation by inducing the expression of the ribosome and translation machinery genes, and by inhibiting mitochondrial respiration. Thus, the activity of PKA and TORC1 acts conversely to that of Snf1. Indeed, negative reciprocal regulation between PKA and Snf1, and between the TORC1 and Snf1 signalling pathways, has been documented [43-47].

Under glucose depletion, or with non-fermentative carbon sources, the expression of the TCA cycle, ETC and OXPHOS genes requires transcription complex Hap2/3/4/5 [35,48,49]. HAP complex activity depends on heme cellular levels and, independently, on PKA and Snf1, which suggests that separate pathways can control mitochondrial respiration [21,50]. Activation subunit Hap4 is the only one of the HAP complexes to be up-regulated upon glucose depletion [51]. Part of this Hap4 up-regulation is mediated by transcription factor Cat8, which is induced and activated by Snf1 $[35,38]$. It is noteworthy that lowering glucose levels in aerobic growing yeast increase the amounts of pyruvate directed to mitochondria which, in turn, provides substrates for heme biosynthesis. Consequently, the increased heme cellular level stimulates Hap4 transcriptional activity in a Hap1-dependent manner and independently of Snf1. These results suggest that the glucose repression of respiration 
is partly due to the low metabolic flux in the TCA cycle and, therefore, to the low cellular heme level under high glucose [52].

To deepen in the putative role of eIF5A in mitochondrial function, we studied the need for eIF5A to metabolise non-fermentative carbon sources through respiration and eIF5A expression regulation under fermentative and respiratory conditions. We herein document that isoform Tif51A, but not Tif51B, is required for growth in media with glycerol and ethanol as carbon sources. Under these conditions, TIF51A was up-regulated in a Hap1and Snf1-dependent manner, and the depletion of TIF51A reduced oxygen consumption, but full eIF5A hypusination was not required to maintain high respiration levels. Our results suggest that during the diauxic shift, TIF51A is initially repressed by reduced TORC1 activity, but later it is Hap1-induced due to the increase in the metabolic flux in the TCA cycle and, consequently, in heme cellular levels. Altogether, our results suggest that the Tif51A isoform of yeast eIF5A responds to the metabolic state of cells to promote mitochondrial respiration.

\section{Results}

2.1. The Tif51A Isoform of Yeast eIF5A Is Required for Respiration and Growth with Non-Fermentative Carbon Sources

S. cerevisiae preferentially ferments glucose, even in the presence of oxygen but, upon glucose deprivation and during growth with non-fermentable carbon sources, many respiratory genes are derepressed and highly induced for energy production [35-37]. As different studies suggest a role of eIF5A in mitochondrial functioning and based on the recently described participation of hypusination and polyamines in modulating the expression of the mitochondrial proteins involved in respiration [34], we were interested in investigating whether eIF5A is actually needed for yeast respiration. To do so, we carried out some experiments on non-fermentable substrates, such as glycerol and ethanol, or a mainly respiratory substrate as galactose, to show different degrees of respiratory rates [39]. Under these conditions, mitochondrial oxidative phosphorylation processes are mandatory for cell growth and proliferation. At semi-restrictive temperatures, growth defects of the temperature-sensitive tif51A-1 mutant, carrying a single (Pro83 to Ser) mutation in the yeast Tif51A isoform of eIF5A, and more severe defects of the tif51A-3 mutant, carrying a double (Cys39 to Tyr, Gly118 to Asp) mutation, but not of strain tif51B $\Delta$, were observed (Figure 1a). Next, we assessed the expression of the two eIF5A isoforms upon growth under non-fermentative conditions, and we observed regulation in opposite ways. While the mRNA levels of TIF51A significantly increased, TIF51B levels lowered compared to glucose (Figure 1b).

In order to more directly explore the requirement of eIF5A in mitochondrial respiration, we measured the oxygen consumption rate in both wild-type (WT) and eIF5A temperaturesensitive mutant cells. The relative oxygen consumption in both mutant cells at a nonpermissive temperature was significantly reduced compared to the WT strain, especially in mutant tif51A-3 (Figure 1c). Minor differences were also observed at the permissive temperature between the wild type and mutants in line with the expected slight loss of function of these Tif51A mutations [4,53]. To take advantage of the fact that the last eIF5A hypusination step is not essential in yeast cells [54], we investigated the implication of full hypusination in the requirement of eIF5A for cell respiration. However, no differences in the oxygen consumption rate were observed between the wild type and the $\mathrm{DOHH}$ (LIA1) mutant cells (Figure 1e). Collectively, these results indicate that mitochondrial respiration is compromised when the yeast Tif51A isoform of eIF5A is lacking, regardless of its hypusination state. 


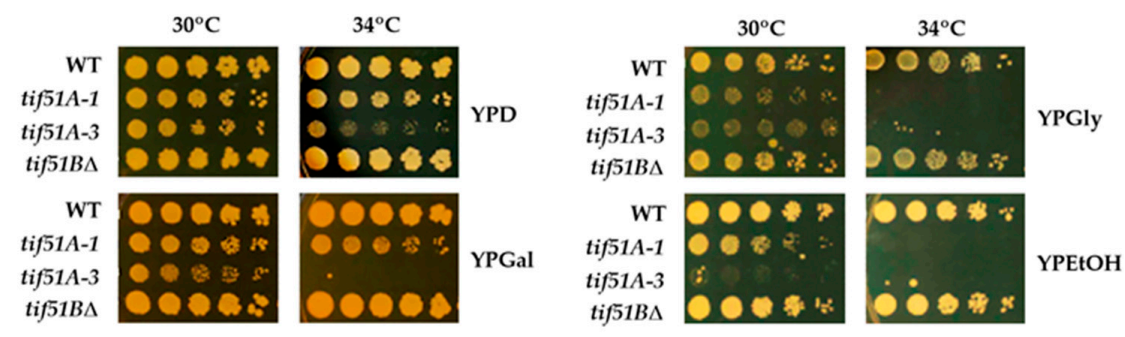

(a)

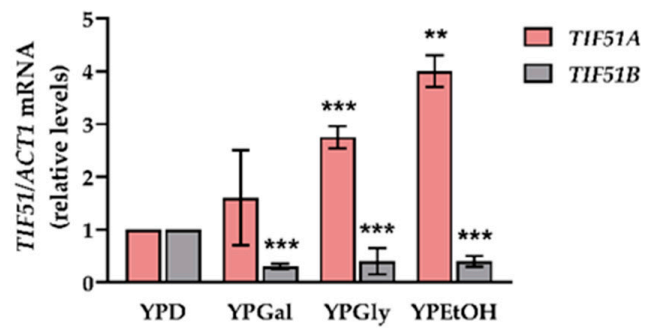

(b)

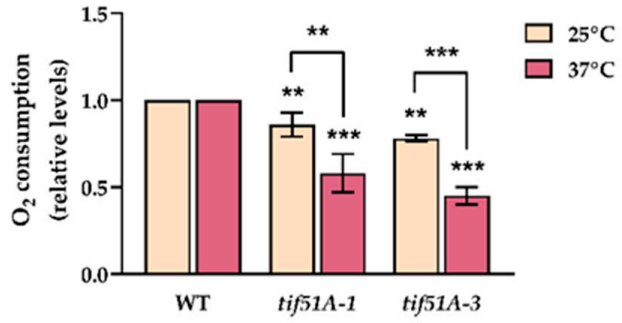

(c)

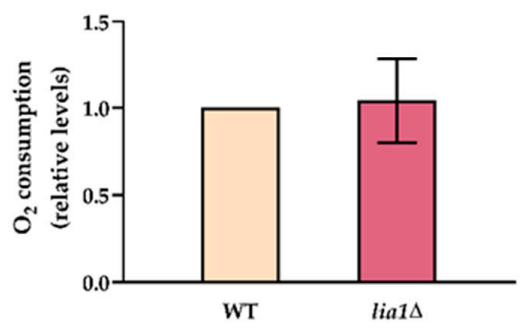

(e)

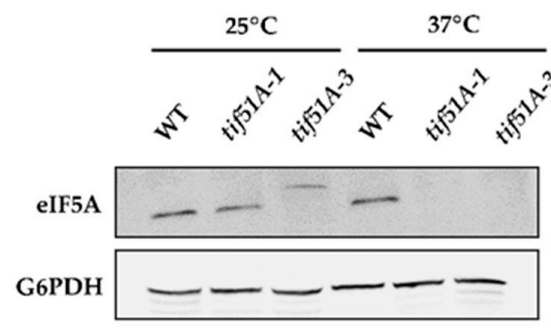

(d)

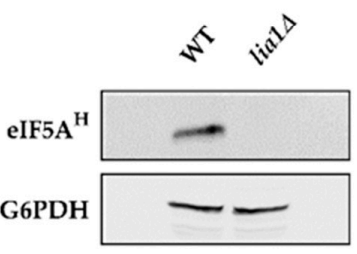

(f)

Figure 1. TIF51A is required for respiration independently of hypusination. (a) Growth of the WT, tif51A-1, tif51A-3 and tif51B $\triangle$ strains was tested in YEP medium containing $2 \%$ glucose (YPD), $2 \%$ galactose (YPGal), $2 \%$ glycerol (YPGly) or $2 \%$ ethanol (YPEtOH) at the indicated temperatures. (b) The WT cells were grown in YPD, YPGal, YPGly or YPEtOH to the exponential phase $\left(\mathrm{OD}_{600}\right.$ of 0.5). Relative TIF51A and TIF51B mRNA levels were determined. (c) The WT, tif51A-1 and tif51A-3 strains were grown in YPGal at permissive temperature $\left(25^{\circ} \mathrm{C}\right)$ and transferred to non-permissive temperature $\left(37^{\circ} \mathrm{C}\right)$ for $4 \mathrm{~h}$ until an $\mathrm{OD}_{600}$ of 1.5-2 was reached. Relative oxygen consumption rates are shown. (d) Western blotting of eIF5A in the WT, tif51A-1 and tif51A-3 cells at $25^{\circ} \mathrm{C}$ and $37^{\circ} \mathrm{C}$ showing eIF5A depletion. Glucose-6-phosphate dehydrogenase $(\mathrm{G} 6 \mathrm{PDH})$ protein levels were used as loading controls. tif51A-3 mutated protein migrates slightly more slowly than the wild-type Tif51A and tif51A-1 mutant due to the mutation of glycine 118 to aspartic. (e) The WT and lia1 $\Delta$ strains were grown in YPGal at $30{ }^{\circ} \mathrm{C}$ until an $\mathrm{OD}_{600}$ of 1.5-2 was reached. Relative oxygen consumption rates are shown. (f) Western blotting of hypusinated eIF5A in the WT and lia1 $\Delta$ showing differences in hypusination. G6PDH protein levels were used as the loading controls. $(\mathbf{b}, \mathbf{c}, \mathbf{e})$ The results are shown as the means \pm SD of three independent experiments and expressed in relation to the value for the $2 \%$ glucose condition or the WT. Statistical significance was measured by a Student's $t$-test in relation to the $2 \%$ glucose condition or WT. ${ }^{* *} p<0.01$, *** $p<0.001$. 


\subsection{Snf1 and Hap1 Signalling Pathways Are Involved in TIF51A Induction under Respiratory Conditions}

As previously described, TIF51A expression was induced in the cells grown with non-fermentable carbon sources glycerol and ethanol, which are used for the oxidative metabolism of mitochondria. We aimed to investigate the mechanism exerted to achieve distinct modulations in eIF5A abundance. PKA, Snf1 and the heme responsive Hap1 and Hap2/3/4 complex are the main factors involved in the metabolic reprograming between two alternative physiological states: fermentation and respiration. PKA affects gene expression, mostly by proteins Msn2 and Msn4, known as general stress-responsive transcription factors. The activators Msn2/Msn4 are down-regulated by PKA under high glucose, and up-regulated by Snf1 under respiratory conditions, which contribute to the adaptive response to respiration [55-57]. We, hence, used mutants hap $1 \Delta$, snf1 $\Delta$ and $m s n 2 \Delta$, which grew well in $2 \%$ glucose media and still grew in the media with a non-fermentative carbon source, although snf1 $\Delta$ displayed a major growth defect (Figure 2a). However, we were unable to work with the hap $4 \Delta$ mutant in the media with ethanol or glycerol as the deletion of any Hap complex subunit did not enable cells to grow under these conditions (Figure 2a and [48]). We determined the mRNA levels of TIF51 $A$ when cells were grown under non-fermentable substrates. Mutants hap $1 \Delta$ and snf1 $\Delta$ showed no increase in the TIF51A levels compared to the WT or $m s n 2 \Delta$ (Figure $2 b$ ). We established the expression of the flavoprotein subunit of the mitochondrial enzyme succinate dehydrogenase (SDH1) as an additional control, which is induced under respiratory conditions. We found that the mRNA levels were affected only in hap $1 \Delta$ and snf1 $\Delta$ (Figure 2c). These results indicate that in the cells grown in the non-fermentable carbon sources, the Hap1p and Snf1p pathways play a role in the up-regulation of eIF5A expression. Based on these results, we hypothesised that Hap1 could influence respiration through eIF5A activation, among its other already known target genes.
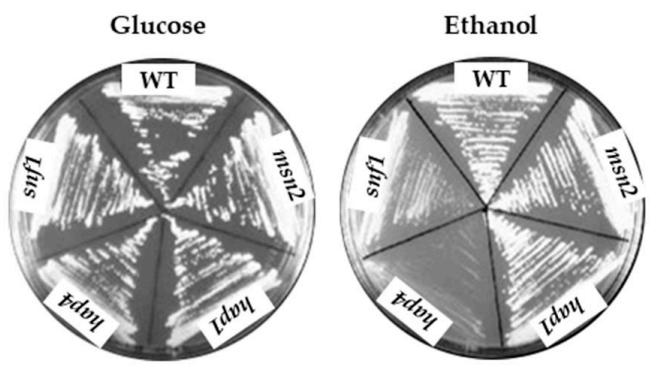

(a)

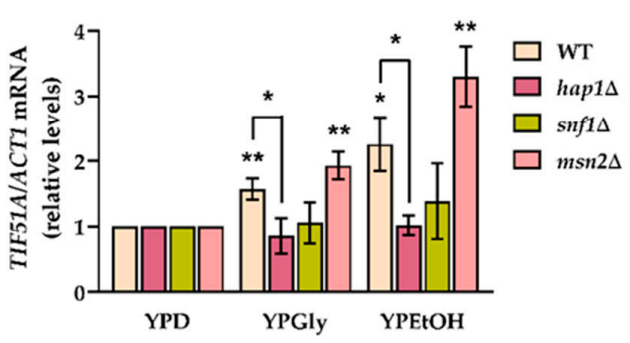

(b)

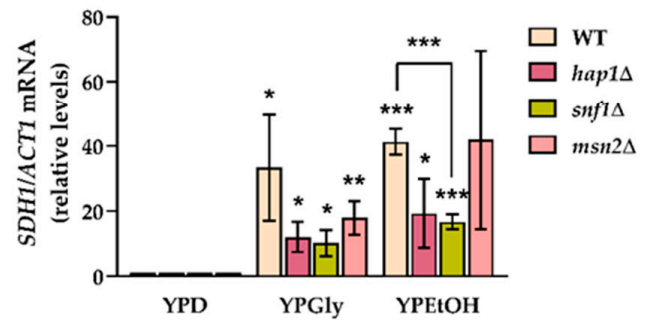

(c)

Figure 2. The Hap1 and Snf1 signalling pathways are required for TIF51A induction under respiratory conditions. (a) Growth of the WT, hap $1 \Delta, \operatorname{snf} 1 \Delta, m s n 2 \Delta$ and hap $4 \Delta$ strains on YEP medium plates containing $2 \%$ glucose or $2 \%$ ethanol. (b,c) The WT, hap1 $\Delta$, snf1 $\Delta$ and $m s n 2 \Delta$ strains were grown in YEP medium containing $2 \%$ glucose, $2 \%$ glycerol or $2 \%$ ethanol to the exponential phase $\left(\mathrm{OD}_{600}\right.$ of 0.5$)$. Relative TIF51A (b) and SDH1 (c) mRNA levels were determined. The results are shown as the means \pm SD of three independent experiments and expressed in relation to the value for the $2 \%$ glucose condition. Statistical significance was measured by a Student's $t$-test in relation to the $2 \%$ glucose condition or WT. ${ }^{*} p<0.05$, ${ }^{* *} p<0.01,{ }^{* * *} p<0.001$. 


\subsection{TIF51A Expression Drops during the Diauxic Shift But Subsequently Increases in a Hap1-Dependent Manner}

We aimed to investigate whether the up-regulation of TIF51A expression under nonfermentative carbon sources would also be reflected by up-regulation when the cells grown in glucose media underwent a metabolic shift from fermentation to respiration, and whether this regulation would also be mediated by Hap1. To test this, we measured and compared the mRNA levels of the two eIF5A isoforms in the WT and hap1 $\Delta$ mutant cells in the exponential and post-diauxic growth phases in a YPD batch culture for up to 4 days before reaching the stationary phase and entering the quiescent state (Figure $3 a$ ). Figure $3 \mathrm{~b}$ shows how the mRNA levels of TIF51A significantly increased to almost 2 -fold in the WT after $48 \mathrm{~h}$ vs. the expression under exponential growth (time 0 ), but remained constant, or even slightly lowered, in hap $1 \Delta$. However, the TIF51B levels significantly and continuously decreased (Supplementary Figure S1). To compare the regulation of TIF51 $A$ with that of another translation factor, we studied translation initiation factor eIF2A expression levels. In the WT strain, with no differences in the hap $1 \Delta$ strain, the eIF $2 A$ mRNA levels slowly lowered from $24 \mathrm{~h}$, which continued up to $96 \mathrm{~h}$ of incubation in YPD (Figure 3c). Our result with eIF2A agrees with previous results, which show that the expression of most translation factors decreases as cells enter the post-diauxic phase and face lack of glucose [51]. To confirm the transition to a respiratory metabolism, we measured TCA enzyme subunit SDH1 expression and observed a substantial increase after the metabolic switch in both strains: WT and hap1s (Figure 3d). An increase in genes TCA, ETC and OXPHOS under respiratory conditions occurs mainly under the control of Hap2/3/4, and Hap1 activity is also required for some genes [21,35,48,49,58]. The up-regulation of Hap4 upon glucose depletion has also been documented [51]. In our experiment, we observed a marked increase in the HAP4 mRNA levels at $24 \mathrm{~h}$ of culture in the WT cells (Figure 3e). Interestingly, HAP1 also showed a 5-fold increase at $24 \mathrm{~h}$ and remained significantly up-regulated for longer times (Figure 3f). Finally, we also checked any variation in the eIF5A protein levels, although using the anti-eIF5A antibody cannot discriminate between isoforms Tif51A and Tif51B, and the eIF2A protein as the control. As shown in Figure 3g,h, the eIF5A protein level dropped to almost undetectable levels after 24 $h$ of growth in YPD, which corresponds to the diauxic shift. This level returned to the initial levels at $72 \mathrm{~h}$. This result may reflect, on the one hand, the observed reduction in TIF51B expression but, given the much higher TIF51A expression under the basal conditions [10], and as TIF51A mRNA does not drop at $24 \mathrm{~h}$, this scenario suggests the down-regulation of Tif51A at the translation or protein stability levels. On the other hand, the later recovery of the Tif51A protein level may result from the increase in its mRNA levels after $48 \mathrm{~h}$ (Figure 3g,h).

Altogether, these results point out the specific requirement of Hap1 for inducing TIF51A after a shift from fermentation to respiratory growth, but also indicate that eIF5A regulation clearly differs from other translation factors. While the expression of most translation factors, if not all, decreased after the metabolic shift, Tif51A showed a very different and, possibly dual, regulation. On the one hand, its expression drastically dropped immediately after the diauxic change, which suggests a rapid response to lowering glucose levels. On the other hand, this decrease was followed by a progressive increase in expression, which may imply that this eIF5A isoform is likely to play a role in the respiratory process. 


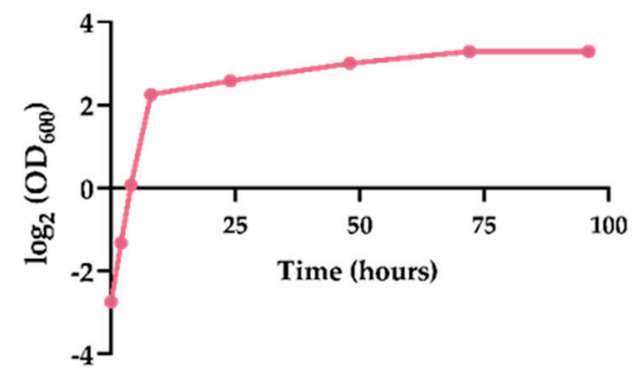

(a)

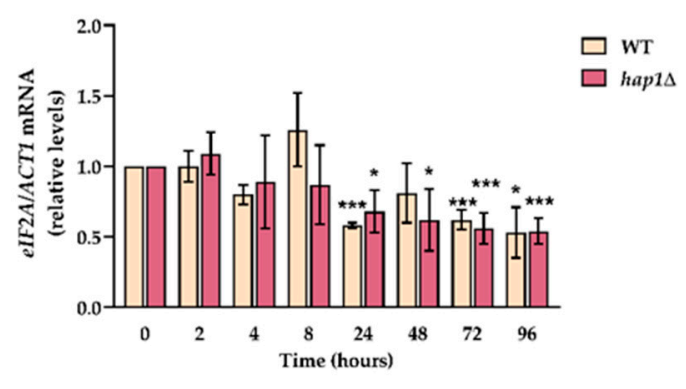

(c)

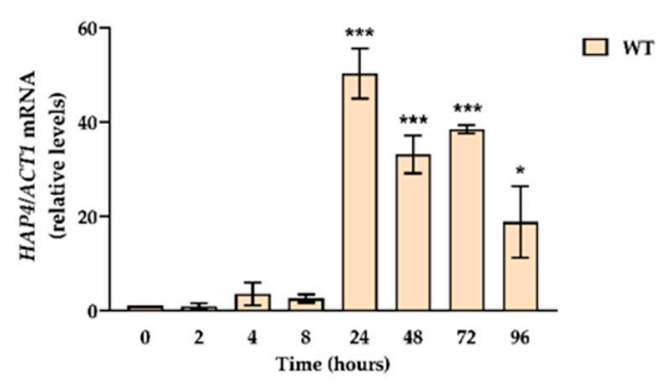

(e)

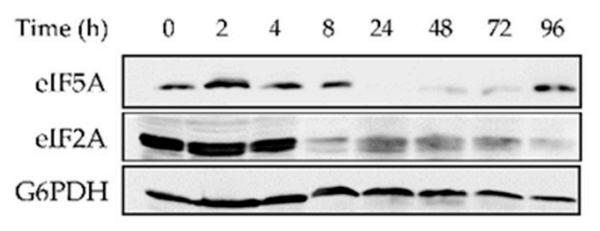

(g)

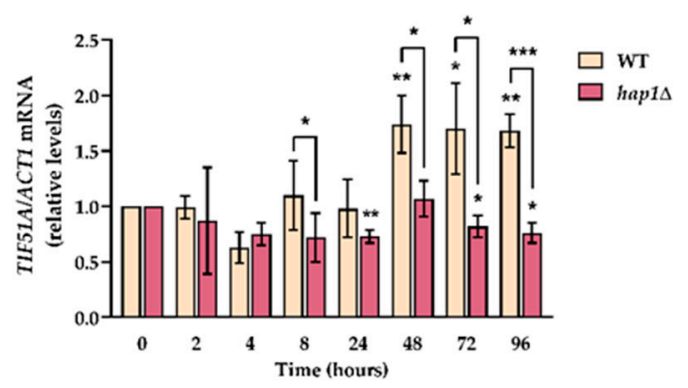

(b)

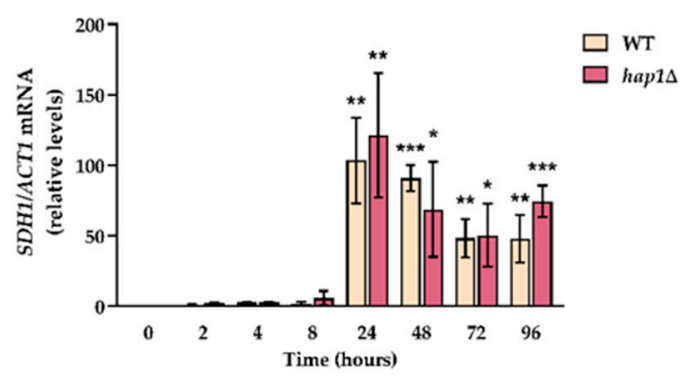

(d)

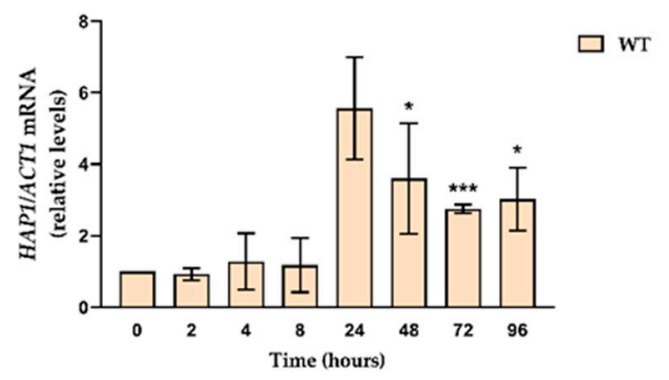

(f)

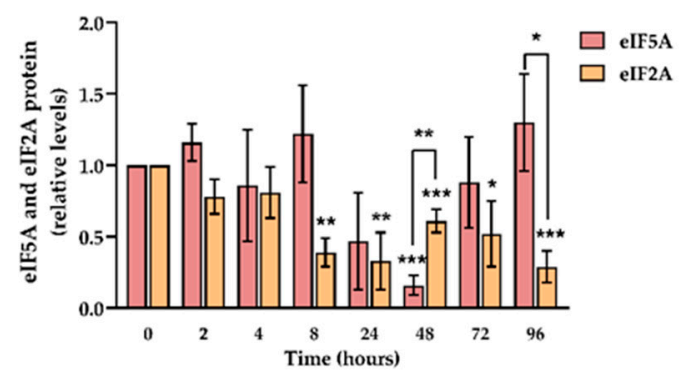

(h)

Figure 3. Tif51A expression drops during glucose exhaustion but recovers in a Hap1-dependent manner in the post-diauxic phase. (a) The WT and hap1 $\triangle$ cells were grown in YPD medium for $96 \mathrm{~h}$ and samples were collected at the indicated time points. (b-f). Relative TIF51A (b), eIF2A (c), SDH1 (d), HAP4 (e) and HAP1 (f) mRNA levels were determined. (g,h). A representative Western blotting experiment $(\mathbf{g})$ and quantification analysis $(\mathbf{h})$ of the eIF5A and eIF2A protein levels in the WT cells at the indicated time points. G6PDH protein levels were used as loading controls. The results are shown as the means \pm SD of three independent experiments and are expressed in relation to the value at time 0 . Statistical significance was measured by a Student's $t$-test in relation to time 0 . ${ }^{*} p<0.05,{ }^{* *} p<0.01,{ }^{* * *} p<0.001$.

\subsection{Glucose Availability and TORC1 Regulate eIF5A Expression}

In an effort to understand eIF5A regulation at the YPD incubation times when the glucose level drops, we decided to study the conceivable TORC1-mediated regulation. Like most organisms, yeast coordinates protein biosynthetic capacity to nutrient availability 
through the TORC1 signal transduction pathway. Under unfavourable growth conditions, TORC1 is inactive, which leads to a slow reduction in translation and synthesis of ribosomal components [59-61].

We confirmed that TORC1 signalling inhibition by rapamycin treatment led to the rapid and pronounced down-regulation of the mRNA levels of the two eIF5A isoforms (TIF51A and TIF51B) and of that of eIF2A (Figure 4a). Likewise, upon TORC1 deactivation, the protein levels of both eIF5A and eIF2A translation factors significantly lowered (Figure $4 \mathrm{~b}$ ). To further prove the regulation upon glucose availability, we studied the mRNA levels of TIF51A in three different scenarios (described in the Materials and Methods section): (1) glucose concentration drops from 2 to $0.1 \%$; (2) glucose concentration rises from 0.1 to $2 \%$; (3) the same increase in glucose concentration as (2) but supplemented with rapamycin. The results showed that the TIF51A levels lowered after a drop in glucose concentration to $0.1 \%$, but were rescued when glucose was added back to cells at regular levels (Figure 4c,d). Moreover, rapamycin treatment, even with excess glucose, did not rescue the higher levels reached in scenario 2, which implies a TORC1-mediated response to glucose availability (Figure 4e). No big differences were observed between the TIF51A and $e I F 2 A$ mRNA levels in the three scenarios, which means that both translation factors are regulated in the same way upon changes in nutrient accessibility.

\subsection{An Increase in the Metabolic Flux in the TCA Cycle and at Heme Cellular Levels Up-Regulates TIF51A in a Hap1-Dependent Manner}

The respiratory process is controlled by the carbon source, together with oxygen and heme levels. The above-stated experiments indicate TIF51A regulation under respiratory conditions by Hap1, which is consistent with previous observations [17]. Hap1 is known to respond to both heme and non-fermentable energy. As Zhang et al. described [52], marked pyruvate transport into mitochondria results in high heme levels and, thus, enhanced Hap1 and Hap2/3/4/5 complex activities. Heme synthesis starts in mitochondria and is limited by TCA and succinyl-CoA availability. To better understand the possible regulation of eIF5A by Hap1, we investigated whether the heme levels and flux into the TCA cycle are critical for TIF51A transcriptional regulation.

We examined the TIF51A expression in the WT, hap $1 \Delta$, mpc1 $\Delta$ and pda1 $\Delta$ cells. Pda1 is a subunit of the pyruvate dehydrogenase complex which catalyses the conversion of pyruvate into acetyl-CoA in mitochondria, while Mpc1 is a pyruvate transporter localised in the inner mitochondrial membrane. We observed that both the TIF51A and SDH1 expression levels in galactose medium significantly lowered in hap $1 \Delta, m p c 1 \Delta$ and $p d a 1 \Delta$ compared to the WT (Figure 5a,b). We interpret these results to mean that the metabolic flux into the TCA cycle regulates eIF5A expression, most likely by regulating Hap1 expression.

As Zhang et al. stated [52], the effect of increasing heme levels on HAP transcription appears to be more significant in those cells grown in glucose than in galactose. To determine whether the heme level is limiting for TIF51A transcription in WT cells, we added 5-aminovulenic acid (ALA, the second metabolite of the heme biosynthesis pathway) or hemin (heme derivative) to the cells grown in the rich media containing glucose. We found that the addition of extracellular ALA or hemin increased TIF51A expression almost 2-fold, and a similar increase was observed for HAP1 and SDH1 expression (Figure 5c-e). Altogether, these results suggest that TIF51A transcription is regulated by Hap1 which, in turn, is regulated by heme and by the metabolic flux into the TCA cycle. This could also explain the increase in TIF51A expression that took place during the diauxic shift (Figure $3 b$ ) when the metabolic flux into mitochondria increased upon glucose exhaustion. 

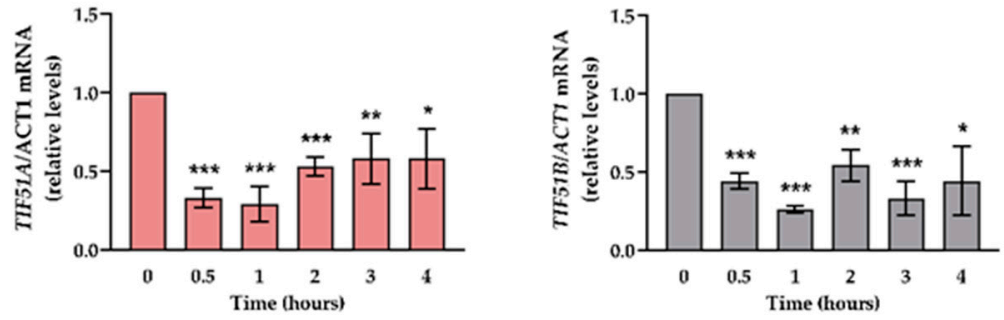

(a)
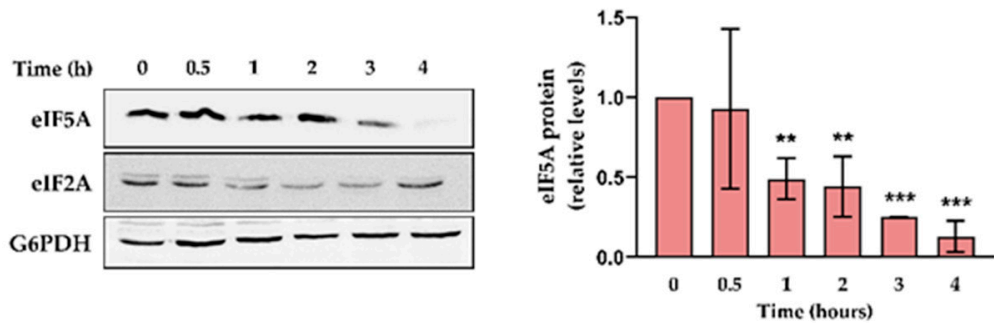

(b)
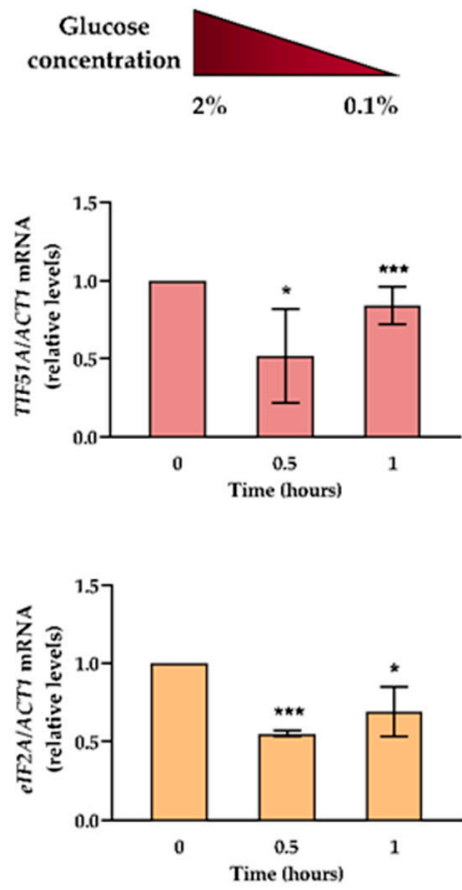

(c)
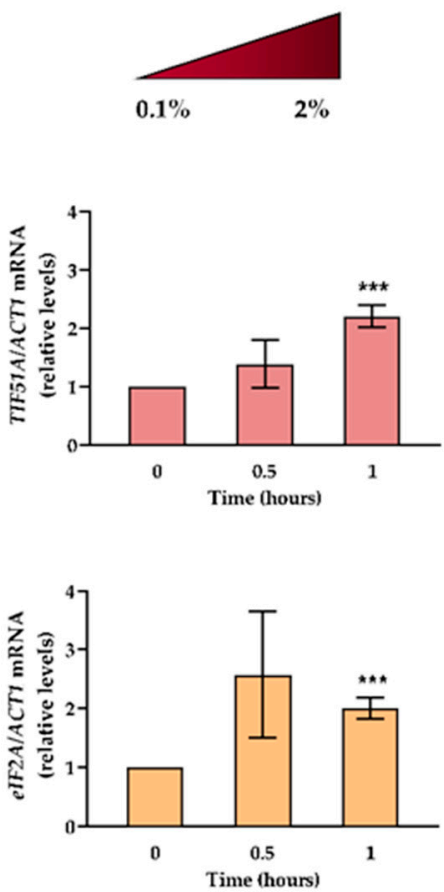

(d)
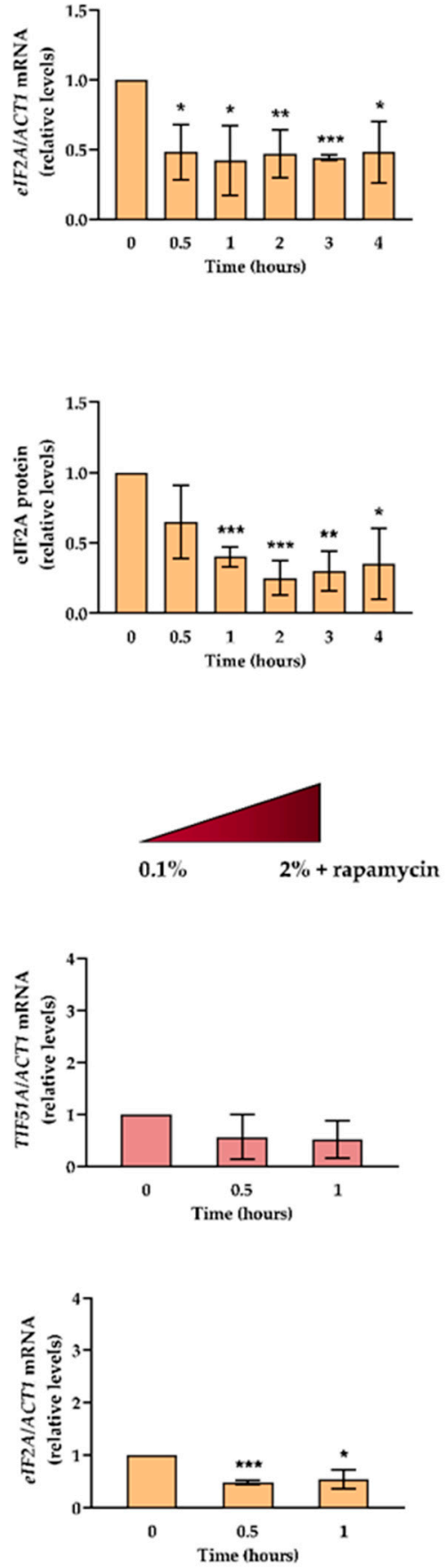

(e)

Figure 4. eIF5A expression is regulated by glucose concentration and TORC1 pathway. $(\mathbf{a}, \mathbf{b})$ WT cells were grown in YPD medium with the addition of $200 \mathrm{ng} / \mathrm{mL}$ rapamycin for $4 \mathrm{~h}$. (a) The relative TIF51A, TIF51B, and $e I F 2 A$ (from left to right) mRNA levels were determined. (b) Western blotting and quantification analysis of proteins eIF5A and eIF2A (from left to right). G6PDH protein levels were used as loading controls. A representative experiment is shown of three independent experiments. (c) The WT cells were grown in the YEP medium containing $2 \%$ glucose and transferred to the YEP medium containing $0.1 \%$ glucose for $1 \mathrm{~h}$. (d,e) The WT cells were grown in the YEP medium containing $0.1 \%$ glucose and transferred to the YEP medium containing $2 \%$ glucose without (d) or with (e) the addition of rapamycin for $1 \mathrm{~h}$. (c-e) The relative TIF51A (up) and eIF2A (down) mRNA levels were determined. (a-e) The results are shown as the means $\pm \mathrm{SD}$ of three independent experiments and are expressed in relation to the value for time 0 . Statistical significance was measured by a Student's $t$-test in relation to time $0 .{ }^{*} p<0.05,{ }^{* *} p<0.01,{ }^{* * *} p<0.001$. 


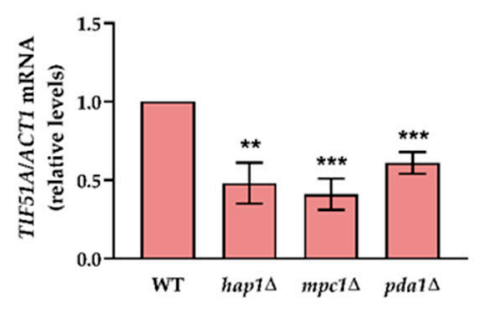

(a)

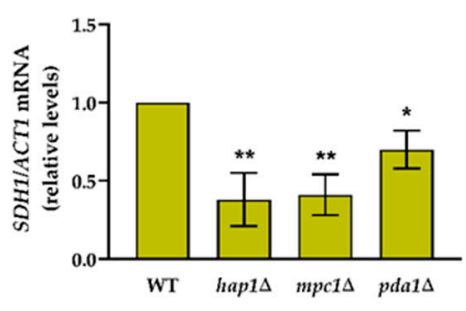

(b)

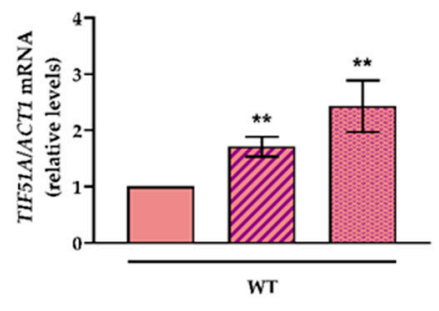

(c)

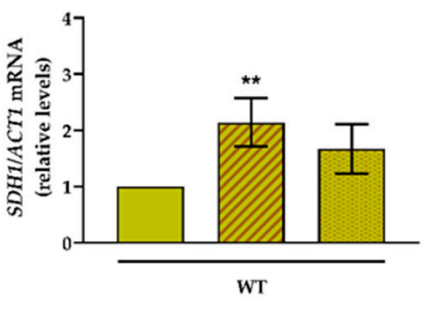

(d)

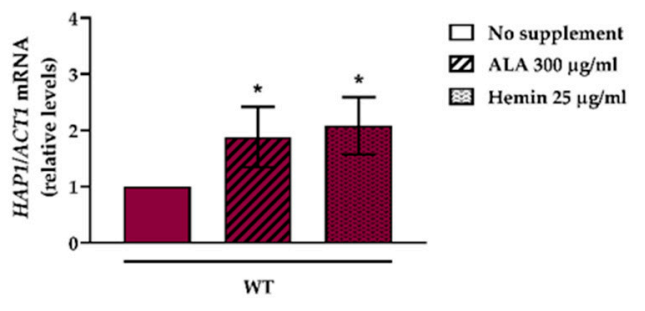

(e)

Figure 5. eIF5A expression is regulated by the metabolic flux into the TCA cycle and heme cellular levels. (a,b) The WT, hap $1 \Delta, m p c 1 \Delta$ and $p d a 1 \Delta$ strains were grown in YPGal medium for $24 \mathrm{~h}$. The relative TIF51A (a) and SDH1 (b) mRNA levels were determined. The results are expressed in relation to the WT value. (c-e) The WT cells were grown in YPD medium with or without the addition of ALA $(300 \mu \mathrm{g} / \mathrm{mL})$ or hemin $(25 \mu \mathrm{g} / \mathrm{mL})$ for $24 \mathrm{~h}$. The relative TIF51A (c), SDH1 (d) and HAP1 (e) mRNA levels were determined. The results are expressed in relation to the value for the no supplement condition. (a-e) and are shown as the means \pm SD of three independent experiments. Statistical significance was measured by a Student's $t$-test. ${ }^{*} p<0.05,{ }^{* *} p<0.01,{ }^{* * *} p<0.001$.

\subsection{TIF51A Is Regulated under Iron Deficiency in a Hap1-Dependent Manner}

Respiration is a highly iron-consuming process as both the TCA cycle and ETC require iron and heme in many steps. Indeed, during iron starvation, cells are unable to grow under non-fermentable carbon sources. Iron deficiency regulation in S. cerevisiae involves metabolic remodelling, which is achieved by changes in gene expression at the transcriptional and post-transcriptional levels to prioritise iron-dependent essential cellular processes over non-essential processes, including mitochondrial respiration (reviewed in [62]). According to our previous results, we hypothesised that under iron starvation, respiratory process inhibition would also involve the down-regulation of TIF51A expression.

The mRNA levels of the two eIF5A isoforms were determined under iron deficiency to test the possible iron-dependent activity of eIF5A. Iron starvation significantly affected the expression of the two isoforms. While TIF51A expression decreased in a time-dependent manner, TIF51B expression increased almost 4-fold (Figure 6a). Due to the very low basal TIF51B expression, its increase did not compensate the down-regulation of TIF51A, and eIF5A protein levels (corresponding to both eIF5A isoforms recognized by the antibody) decreased under iron depletion (Supplementary Figure S2). The increased but still low expression of the Tif51B isoform must be insufficient to support yeast growth because we observed that the complete depletion of the Tif51A protein (using TIF51A temperature sensitive mutants at restrictive temperature) rendered it sensitive to iron starvation (Supplementary Figure S3). Next, we determined if eIF5A regulation under iron deficiency was based on a transcriptional mechanism and attempted to identify the implicated factor. To that end, we tested the expression of both isoforms under iron sufficiency or deficiency conditions in the WT, hap $1 \Delta$ and hap $4 \Delta$ mutant cells. We found that only for hap $1 \Delta$ cells the TIF51A mRNA levels remained unchanged and transcriptional regulation was lost, which indicate that Hap1 is responsible for eIF5A regulation under iron deficiency (Figure 6b). The synthesis of the iron-containing heme directly correlates with iron availability, and it has been shown that, under iron-limiting conditions, the cytochrome c-encoding CYC1 gene is 
transcriptionally down-regulated via the Hap1 transcription factor with some contribution made by the Hap2/3/4/5 complex [63]. We observed that the CYC1 mRNA levels were down-regulated and almost undetectable when iron was absent (Figure $6 \mathrm{c}$ ). With the case of hap $1 \Delta$ and hap $4 \Delta$ cells, the $C Y C 1$ levels substantially lowered under the iron-sufficient condition and most of the down-regulation was lost in the single mutants, which agrees with previous data [63]. Finally, Hap1 was also important for TIF51B regulation as the induction that occurred in the WT strain under iron depletion was blocked when cells were Hap1-deficient (Figure 6d). This result can be interpreted by the fact that lack of heme, in this case caused by limited iron availability, converts Hap1 in a repressor that downregulates ROX1, which is necessary for inducing TIF51B [22]. Taken together, these results reinforce the idea of TIF51A expression regulation at the transcriptional level by Hap1 to up- or down-regulate its expression depending on the cell's metabolic requirements.

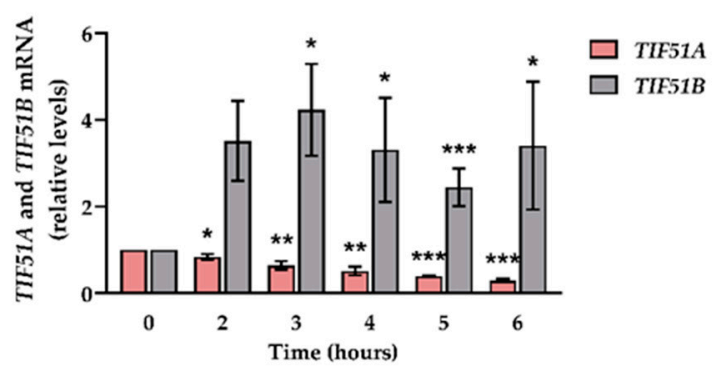

(a)

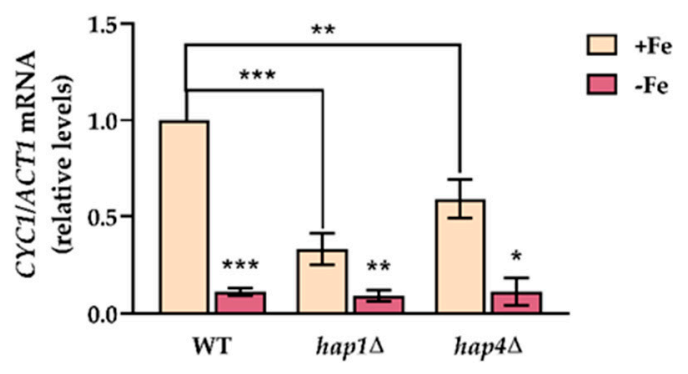

(c)

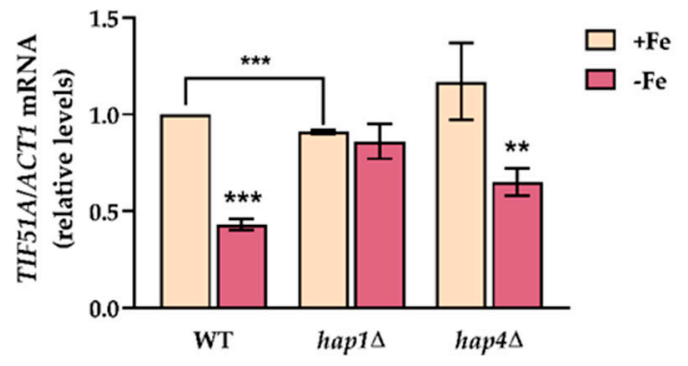

(b)

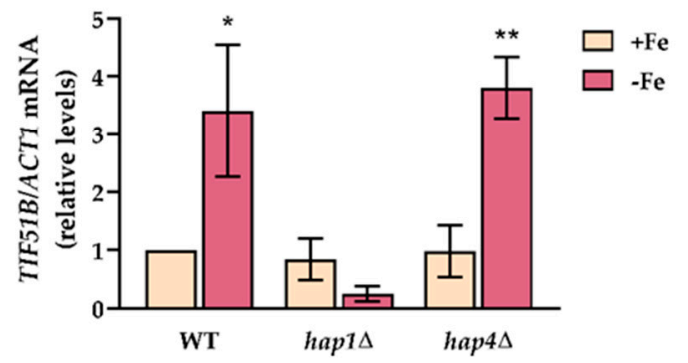

(d)

Figure 6. Iron deficiency down-regulates TIF51A and up-regulates TIF51B in a Hap1-dependent manner. (a) The WT cells were grown in SC medium with the addition of $100 \mathrm{mM}$ BPS and samples were collected at the indicated time points. The relative TIF51A and TIF51B mRNA levels were determined. The results are expressed in relation to the value at time 0. (b-d) The WT, hap1 $\Delta$ and hap $4 \Delta$ strains were grown in SC medium with or without the addition of $100 \mathrm{mM} \mathrm{BPS} \mathrm{for} 7 \mathrm{~h}$. The relative TIF51A (b), CYC1 (c) and TIF51B (d) mRNA levels were determined. The results are expressed in relation to the value of the WT strain without treatment. (a-d) The results are shown as the means \pm SD of three independent experiments. Statistical significance was measured by a Student's $t$-test. ${ }^{*} p<0.05,{ }^{* *} p<0.01,{ }^{* * *} p<0.001$.

\section{Discussions}

The adaptation of the cellular metabolism to external circumstances is important for those unicellular systems that must deal with a continuously changing environment, but also for multicellular ones as redirecting metabolism can promote different cellular functions. One important example of metabolic adaptation is the well-known Warburg effect, by means of which most tumour cells sustain aerobic glycolysis with glucose fermentation into lactate, unlike complete glucose oxidation by mitochondria, to meet their bioenergetic and anabolic demands $[64,65]$. In fact, it has been proposed that all high proliferating cells adapt their metabolism to facilitate the uptake and incorporation of nutrients into the biomass needed to produce a new cell (aerobic glycolysis) over the promotion of highefficient ATP synthesis in the quiescent (differentiated) state (mitochondrial OXPHOS). This also applies to microorganisms like yeast cells, which prefer the fermentation of glucose 
when it abounds, but change to mitochondrial respiration when glucose is scarce [66]. Understanding how cells adapt their metabolism to meet demands is relevant because wrong adaptation can have pathological consequences. Previous studies (detailed in the Introduction) as well as the present one suggest a role of eIF5A in promoting mitochondrial metabolism.

Our study addresses how eIF5A expression is regulated to adapt it to metabolic requirements. Although eIF5A is a highly expressed protein and has been described as one of the 20 most abundant proteins in proliferating cells [67], 2- to 4-fold increases in yeast cells took place under respiratory conditions. Like other proteins involved in translation [59-61], we document a positive regulation by the TORC1 signalling pathway activated under abundant nutrient conditions. In this situation, we expected the main function of cellular eIF5A to facilitate the cytoplasmic translation of the genes encoding proteins with specific amino acids motifs [2,3], although other molecular functions for eIF5A have been described [68]. With low glucose or non-fermentative carbon sources, our results indicate that the Tif51A isoform of yeast eIF5A is up-regulated by Snf1 and Hap1, and Tif51A depletion compromises growth in ethanol or glycerol and reduces oxygen consumption. The reason why more eIF5A protein is needed under this condition when growth has slowed down and, therefore, less cytoplasmic translation is required, is not known. A model summarising our results is show in Figure 7. It is worth highlighting the recent results reported by Puleston et al. [34], who suggest that eIF5A is required for the efficient translation of a subset of mitochondrial proteins, such as succinate dehydrogenase (SDH) and some other TCA cycle and OXPHOS proteins, which carry specific mitochondrial target signals. On the contrary, other TCA enzymes would be less eIF5A-dependent, which eIF5A inactivation would not affect their expression. A search for eIF5A-dependent tripeptide motifs [2] reveals a slight enrichment of these motifs in TCA enzymes but an underrepresentation of these motifs in OXPHOS proteins, both compared to total yeast proteins (Supplementary Figure S4). Interestingly, polyproline motifs are excluded in the polypeptide sequences of both functional groups (Supplementary Figure S4). A more exhaustive investigation will be necessary to identify eIF5A mitochondrial targets and mechanisms involved in the eIF5A control of mitochondrial respiration. The need of eIF5A for synthesizing specific mitochondrial proteins would explain its upregulation under respiratory conditions, when the expression of some of the proteins required for respiration substantially increases (SDH1 mRNA increases more than 100-fold during the diauxic shift, Figure 3d). If this role of eIF5A in the translation of nuclear-encoded mitochondrial proteins is direct, the co-purification of eIF5A with mitochondria [24-26] may indicate that eIF5A is involved in the described translation on the yeast mitochondrial surface, where inner-membrane proteins like SDH are supposed to be cotranslationally targeted to the mitochondria [69].

One outcome of our study was the clearly differential regulation of the yeast eIF5A isoforms. Their opposite regulation by oxygen has been previously documented, with TIF51 $A$ being repressed and TIF51 $B$ activated during hypoxia/anaerobiosis, when hemedependent Hap1 activity controls TIF51B repressor Rox1 expression [17-22]. Here we show that Hap1 is also the main factor that controls TIF51A expression in response to respiratory conditions, heme levels and iron availability. In fact, a putative binding site for Hap1 (CGGnnnTAnCGG, [70]) exists $571 \mathrm{bp}$ upstream of the ATG of TIF51A, but further work should be done to demonstrate the direct regulation of TIF51A expression by Hap1. The control of eIF5A isoforms by Hap1, likely by activating TIF51 $A$ expression and the Rox1 repression of TIF51B under nutrient and oxygen availability, but by repressing TIF51 $A$ and Rox1 under nutrient and/or oxygen scarcity, would allow the opposite regulation of the two paralogue genes with only one factor. It is tempting to suggest that the differential expression of the eIF5A isoforms would promote, in each case, differential metabolic outcomes with Tif51A promoting respiration and Tif51B promoting aerobic glycolysis. To date, there has been no evidence to support this in yeast, although it has been described that the eIF5A-2 isoform of human eIF5A promotes aerobic glycolysis in human hepatocellular 
carcinoma (HCC) [71]. Thus eIF5A-2 overexpression increases growth, glucose uptake and lactate secretion by up-regulating glycolytic enzymes [71], which is precisely the metabolic reprogramming that occurs in most cancer cells [72].

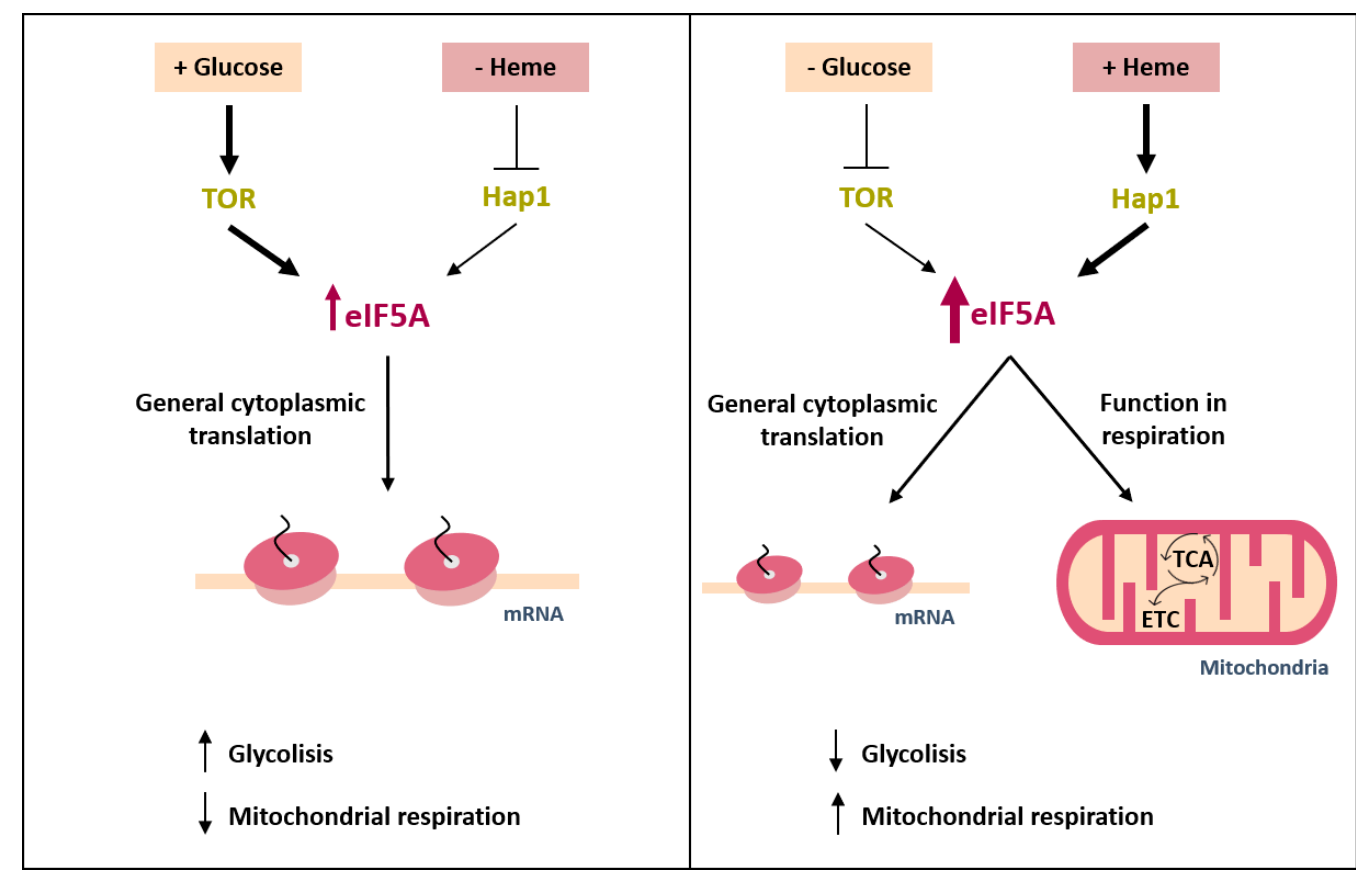

Figure 7. Model of regulation of the translation elongation factor eIF5A expression by nutrient availability through different signalling pathways. Under nutrient availability conditions, glucose signalling via TOR up-regulates eIF5A expression to facilitate cytoplasmic translation, and glycolysis predominates over mitochondrial respiration. Under low glucose and/or non-fermentative carbon sources, TOR positive eIF5A regulation is inhibited, but eIF5A expression is up-regulated by the increase in heme levels and subsequent Hap1 activation. In these conditions, eIF5A promotes, additionally to cytoplasmic translation, not-well known functions in mitochondrial respiration.

Several aspects of TIF51A regulation by the metabolic status of cells will have to be explored in future studies. We showed that the up-regulation of TIF51A under nonfermentative carbon sources also depends on Snf1 kinase. However, we do not know if this regulation is executed by the release of Mig1-repression or through transcription activators under the control of Snf1, such as Cat8, which controls the derepression of HAP4 under respiratory conditions [35]. The control of TIF51A expression by glucose and TORC1 should also be further investigated to elucidate the involved mechanism, which could implicate TORC1 downstream kinase Sch9 because its depletion increases respiration [43]. One of our observations indicates that the deletion mutant in yeast DOHH enzyme lia1s has the same oxygen rate consumption as the WT strain. Differently to mammalians and most eukaryotes, S. cerevisiae DOHH is not essential and shows similar growth to the WT [54]. Our results suggest that full yeast Tif51A hypusination would not be necessary to promote respiration, conversely to the results obtained for mammals [34].

The control by Hap1 and Snf1 of TIF51A expression under respiratory conditions that we herein report is likely to occur at the transcriptional level. However, it has also been previously reported that the posttranscriptional control of TIF51A expression by carbon sources is executed at the mRNA stability level. TIF51A mRNA harbours an ARE (AU-rich) element) at the $3^{\prime}$ UTR (untranslated region), which has been described to stabilise the mRNA on glucose and destabilise it in glycerol media [73]. Although this regulation is opposite to what we show here, with a higher TIF51A mRNA level in glycerol than in glucose, both results may still be compatible if major differences at the transcriptional level would reverse the negative impact of a reduction in TIF51A mRNA stability in 
glycerol media. AREs are also important for mRNA stability regulation and translation upon iron depletion through mRNA binding proteins $\mathrm{Cth} 2$ and $\mathrm{Cth} 4$. Iron deficiency promotes the specific binding of Cth2/4 to ARE-containing mRNAs and down-regulates, among other non-essential processes, mitochondrial respiration [74-76]. Whether TIF51A mRNA is posttranscriptionally regulated through its ARE sequence must be addressed in future studies.

\section{Materials and Methods}

\subsection{Yeast Strains and Growth Conditions}

All the Saccharomyces cerevisiae strains used herein are listed in Table S1. Yeast cells were grown in liquid YPD ( $2 \%$ glucose, $2 \%$ peptone, $1 \%$ yeast extract), YPGal ( $2 \%$ galactose, $2 \%$ peptone, $1 \%$ yeast extract), YPGly ( $2 \%$ glycerol, $2 \%$ peptone, $1 \%$ yeast extract), YPEtOH ( $2 \%$ ethanol, $2 \%$ peptone, $1 \%$ yeast extract) or synthetic complete (SC) media.

A PCR-based genomic disruption technique was employed to replace genomic full length HAP1 ORF with the KanMX marker. Plasmid pFA6a-KanMX6 [77] was used as a template for PCR reactions using primers HAP1-F1 and HAP1-R1 for HAP1 deletion. The resulting cassette was transformed into the WT strain by the lithium acetate-based method [78] and transformants were selected in the YPD medium supplemented with geneticin (G418, Gibco Life Technologies, Waltham, MA, USA).

Experimental assays were performed with the cells exponentially grown for at least four generations at $30^{\circ} \mathrm{C}$ until required $\mathrm{OD}_{600}$. Temperature-sensitive strains were grown at the permissive temperature of $25^{\circ} \mathrm{C}$ until required $\mathrm{OD}_{600}$ and transferred to the nonpermissive temperature of $37^{\circ} \mathrm{C}$ for $4 \mathrm{~h}$ for complete eIF5A depletion. For some experiments described in the text, the media were supplemented with $100 \mu \mathrm{M}$ of bathophenanthrolinedisulphonic acid (BPS, Sigma, St. Louis, MO, USA), $200 \mathrm{ng} / \mathrm{mL}$ of rapamycin (LC Laboratories, Woburn, MA, USA), $300 \mu \mathrm{g} / \mathrm{mL}$ of $\delta$-aminolevulinate (ALA, Sigma) and $25 \mu \mathrm{g} / \mathrm{mL}$ of hemin (Sigma). ALA and hemin were dissolved in water and DMSO at $100 \mathrm{mg} / \mathrm{mL}$ and $10 \mathrm{mg} / \mathrm{mL}$, respectively, and added to media at the indicated concentrations.

\subsection{Western Blot Analysis}

Protein extraction and Western blot analyses were performed as previously described [79]. In brief, a cell culture volume corresponding to $5-10 \mathrm{OD}_{600}$ units was harvested by centrifugation. For protein extraction, cell pellets were washed and resuspended in $200 \mu \mathrm{L}$ of $\mathrm{NaOH} 0.2 \mathrm{M}$ and incubated at room temperature for $5 \mathrm{~min}$ for posterior centrifugation at $12,000 \mathrm{rpm}$ for $1 \mathrm{~min}$. Then samples were resuspended in $100 \mu \mathrm{L}$ of 2X-SDS protein loading buffer (Tris-HCl pH $6.824 \mathrm{mM}$, Glycerol 10\%, SDS 0.8\%, $\beta$-mercaptoethanol $5.76 \mathrm{mM}$, bromophenol blue $0.04 \%$ ) and boiled for $5 \mathrm{~min}$ at $95{ }^{\circ} \mathrm{C}$. Afterwards, lysates were centrifuged at $3000 \mathrm{rpm}$ for $10 \mathrm{~min}$ at $4{ }^{\circ} \mathrm{C}$ to remove cell debris and insoluble proteins, and supernatants were transferred to fresh tubes and stored at $-20^{\circ} \mathrm{C}$. The soluble protein content in the extract was quantified by an $\mathrm{OD}_{280}$ estimation in a Nanodrop device (Thermo Fisher Scientific, Waltham, MA, USA) to load equal protein amounts per sample into $15 \%$ SDS-PAGE gels.

SDS-PAGE and Western blot were performed by standard procedures (Bio-Rad Laboratories). Membranes were blocked with 5\% skimmed milk in TBS-T (150 mM NaCl, $20 \mathrm{mM}$ Tris, $0.1 \%$ Tween $20, \mathrm{pH} 7.6$ ) for $1 \mathrm{~h}$ at room temperature and incubated with primary antibodies overnight at $4{ }^{\circ} \mathrm{C}$ against eIF5A (rabbit polyclonal 1:500, Abcam ab137561), hypusinated-eIF5A (FabHpu antibody, 1:600, Genentech, San Francisco, CA, USA), eIF2A (rabbit polyclonal 1:1000, kindly provided by T. Dever) or glyceraldehyde-6-phosphate dehydrogenase (rabbit polyclonal anti-G6PDH antibody, 1:20,000, Sigma A9521). Bound antibodies were detected using the appropriate horseradish peroxidase-conjugated secondary antibodies (1:10,000 Promega). Chemiluminiscent signals were detected with an ECL Prime Western blotting detection kit (GE Healthcare, Chicago, IL, USA) and digitally analysed by the ImageQuant LAS 4000 software (GE Healthcare). Band intensity was normalised against G6PDH bands. At least three replicates of each sample were analysed. 


\subsection{RT-qPCR Analysis}

For the analysis of mRNA levels, total RNA was isolated from yeast cells following the phenol:chloroform protocol. Briefly, a volume of an exponential phase culture corresponding to $10 \mathrm{OD}_{600}$ units was harvested and flash frozen. The cells were resuspended in $500 \mu \mathrm{L}$ of cold LETS buffer ( $\mathrm{LiCl} 0.1 \mathrm{M}$, EDTA pH $8.010 \mathrm{mM}$, Tris-HCl pH $7.410 \mathrm{mM}$, SDS $0.2 \%$ ) and transferred to a screw-cap tube already containing $500 \mu \mathrm{L}$ of sterile glass beads and $500 \mu \mathrm{L}$ of phenol:chloroform (5:1). Then, the cells were broken in a Precellys 24 tissue homogenizer (Bertin Technologies) and centrifuged. The supernatant was transferred o a new tube containing $500 \mu \mathrm{L}$ of phenol:chloroform (5:1) and then to a tube containing $500 \mu \mathrm{L}$ of chloroform:isoamyl alcohol (25:1). The RNA from the top phase was precipitated and finally dissolved in water for later quantification and quality control using a Nanodrop device (Thermo Fisher Scientific).

The reverse transcription and quantitative $\mathrm{PCR}$ reactions were performed as detailed in [80]. Briefly, $2.5 \mu \mathrm{g}$ of the total DNAse-I-(Roche) treated RNA were retrotranscribed using an oligo d(T)18 with Maxima Reverse Transcriptase (Thermo Fisher Scientific). cDNA was labelled with SYBR Pre-mix Ex Taq (Tli RNase H Plus, from Takara) and Cq values were obtained from the CFX96 TouchTM Real-Time PCR Detection System (BioRad). Endogenous ACT mRNA levels were used for normalisation. At least three biological replicates of each sample were analysed, and the specific primers designed to amplify the gene fragments of interest are listed in Table S2.

\subsection{Oxygen Consumption Assays}

Molecular oxygen consumption was measured by a model Oxyview 1 System (Hansatech) and an S1 Clark-type oxygen electrode following the manufacturer's protocol. Cells were grown to an $\mathrm{OD}_{600}$ of 1.5-2 in YPGal medium, and a volume corresponding to 1.0 $\mathrm{OD}_{600}$ was collected and washed with distilled water. The cells were then resuspended in $1 \mathrm{~mL}$ of the YEP medium containing 2\% ethanol and 3\% glycerol, and were transferred to the oxygen consumption chamber, magnetically stirred and maintained at $30^{\circ} \mathrm{C}$. The oxygen content decline was monitored for $15 \mathrm{~min}$ and respiratory rates were determined from the slope. The oxygen consumption rate in the WT cells was set at 1.

Supplementary Materials: Supplementary Materials can be found at https://www.mdpi.com/1422 $-0067 / 22 / 1 / 219 /$ s1.

Author Contributions: Conceptualization, P.A. and M.B.-A.; methodology, P.A., M.B.-A. and M.T.M.P.; validation, M.B.-A. and C.V.-V.; formal analysis, M.B.-A.; investigation, M.B.-A, C.V.-V., A.S. and A.C.; resources, P.A.; data curation, M.B.-A.; writing-original draft preparation, P.A. and M.B.A.; writing-review and editing, P.A., M.B.-A. and M.T.M.-P.; visualization, M.B.-A.; supervision, P.A.; project administration, P.A.; funding acquisition, P.A. All authors have read and agreed to the published version of the manuscript.

Funding: This research was funded by the Spanish Ministry of Science, Innovation and Universities (BFU2016-77728-C3-3-P grant to P.A. and BIO2017-87828-C2-1-P, to M.T.M.-P.) and the Regional Valencian Government [AICO2020/086] to P.A. Funding for open access charge: [BFU2016-77728C3-3-P]. M.B.-A. is a recipient of a predoctoral research contract (FPU2017/03542) from the Spanish Ministry of Science, Innovation and Universities.

Institutional Review Board Statement: Not applicable.

Informed Consent Statement: Not applicable.

Data Availability Statement: Data is contained within the article or supplementary material. The data presented in this study are available in [insert article or supplementary material here].

Acknowledgments: We thank J.E. Pérez-Ortín for his helpful discussion and Thomas Dever for the anti-eIF2A antibody. We are in debt to all the lab members for their helpful discussion and support.

Conflicts of Interest: The authors declare no conflict of interest. 


$\begin{array}{ll}\text { Abbreviations } \\ \text { eIF2A } & \text { Eukaryotic translation initiation factor 2A } \\ \text { eIF5A } & \text { Eukaryotic translation initiation factor 5A } \\ \text { ETC } & \text { Electron transport chain } \\ \text { OXPHOS } & \text { Oxidative phosphorylation } \\ \text { PKA } & \text { Protein kinase A } \\ \text { ROS } & \text { Reactive oxygen species } \\ \text { SDH } & \text { Succinate dehydrogenase } \\ \text { TCA } & \text { Tricarboxylic acid } \\ \text { TORC1 } & \text { Target of rapamycin complex I }\end{array}$

\section{References}

1. Park, M.H.; Wolff, E.C. Hypusine, a polyamine-derived amino acid critical for eukaryotic translation. J. Biol. Chem. 2018, 293, 18710-18718. [CrossRef] [PubMed]

2. Pelechano, V.; Alepuz, P. EIF5A facilitates translation termination globally and promotes the elongation of many non polyprolinespecific tripeptide sequences. Nucleic Acids Res. 2017, 45, 7326-7338. [CrossRef] [PubMed]

3. Schuller, A.P.; Wu, C.C.C.; Dever, T.E.; Buskirk, A.R.; Green, R. eIF5A Functions Globally in Translation Elongation and Termination. Mol. Cell 2017, 66, 194-205.e195. [CrossRef] [PubMed]

4. Li, T.; Belda-Palazón, B.; Ferrando, A.; Alepuz, P. Fertility and polarized cell growth depends on eIF5A for translation of polyproline-rich formins in Saccharomyces cerevisiae. Genetics 2014, 197, 1191-1200. [CrossRef] [PubMed]

5. Gutierrez, E.; Shin, B.S.; Woolstenhulme, C.J.; Kim, J.R.; Saini, P.; Buskirk, A.R.; Dever, T.E. eif5A promotes translation of polyproline motifs. Mol. Cell 2013, 51, 35-45. [CrossRef]

6. Muñoz-Soriano, V.; Domingo-Muelas, A.; Li, T.; Gamero, E.; Bizy, A.; Fariñas, I.; Alepuz, P.; Paricio, N. Evolutionary conserved role of eukaryotic translation factor eIF5A in the regulation of actin-nucleating formins. Sci. Rep. 2017, 7. [CrossRef]

7. Dever, T.E.; Dinman, J.D.; Green, R. Translation elongation and recoding in eukaryotes. Cold Spring Harb. Perspect. Biol. 2018, 10. [CrossRef]

8. Schwelberger, H.G.; Hyun, A.K.; Hershey, J.W.B. Translation initiation factor eIF-5A expressed from either of two yeast genes or from human cDNA. Functional identity under aerobic and anaerobic conditions. J. Biol. Chem. 1993, 268, 14018-14025.

9. Clement, P.M.J.; Henderson, C.A.; Jenkins, Z.A.; Smit-McBride, Z.; Wolff, E.C.; Hershey, J.W.B.; Park, M.H.; Johansson, H.E. Identification and characterization of eukaryotic initiation factor 5A-2. Eur. J. Biochem. 2003, 270, 4254-4263. [CrossRef]

10. Schnier, J.; Schwelberger, H.G.; Smit-McBride, Z.; Kang, H.A.; Hershey, J.W. Translation initiation factor 5A and its hypusine modification are essential for cell viability in the yeast Saccharomyces cerevisiae. Mol. Cell. Biol. 1991, 11, 3105-3114. [CrossRef]

11. Magdolen, V.; Klier, H.; Wöhl, T.; Klink, F.; Hirt, H.; Hauber, J.; Lottspeich, F. The function of the hypusine-containing proteins of yeast and other eukaryotes is well conserved. MGG Mol. Gen. Genet. 1994, 244, 646-652. [CrossRef] [PubMed]

12. Jenkins, Z.A.; Hååg, P.G.; Johansson, H.E. Human EIF5A2 on chromosome 3q25-q27 is a phylogenetically conserved vertebrate variant of eukaryotic translation initiation factor 5A with tissue-specific expression. Genomics 2001, 71, 101-109. [CrossRef] [PubMed]

13. Kaiser, A. Translational control of eIF5A in various diseases. Amino Acids 2012, 42, 679-684. [CrossRef] [PubMed]

14. Nakanishi, S.; Cleveland, J.L. Targeting the polyamine-hypusine circuit for the prevention and treatment of cancer. Amino Acids 2016, 48, 2353-2362. [CrossRef] [PubMed]

15. Ning, L.; Wang, L.; Zhang, H.; Jiao, X.; Chen, D. Eukaryotic translation initiation factor 5A in the pathogenesis of cancers. Oncol. Lett. 2020, 20, 81. [CrossRef] [PubMed]

16. Mathews, M.B.; Hershey, J.W.B. The translation factor eIF5A and human cancer. Biochim. Biophys. Acta Gene Regul. Mech. 2015, 1849, 836-844. [CrossRef] [PubMed]

17. Zitomer, R.S.; Lowry, C.V. Regulation of gene expression by oxygen in Saccharomyces cerevisiae. Microbiol. Rev. 1992, 56, 1-11. [CrossRef]

18. Kastaniotis, A.J.; Mennella, T.A.; Konrad, C.; Torres, A.M.R.; Zitomer, R.S. Roles of Transcription Factor Mot3 and Chromatin in Repression of the Hypoxic Gene ANB1 in Yeast. Mol. Cell. Biol. 2000, 20, 7088-7098. [CrossRef]

19. Klinkenberg, L.G.; Mennella, T.A.; Luetkenhaus, K.; Zitomer, R.S. Combinatorial repression of the hypoxic genes of Saccharomyces cerevisiae by DNA binding proteins Rox1 and Mot3. Eukaryot. Cell 2005, 4, 649-660. [CrossRef]

20. Sertil, O.; Kapoor, R.; Cohen, B.D.; Abramova, N.; Lowry, C.V. Synergistic repression of anaerobic genes by Mot3 and Rox1 in Saccharomyces cerevisiae. Nucleic Acids Res. 2003, 31, 5831-5837. [CrossRef]

21. Zhang, L.; Hach, A. Molecular mechanism of heme signaling in yeast: The transcriptional activator Hap1 serves as the key mediator. Cell. Mol. Life Sci. 1999, 56, 415-426. [CrossRef] [PubMed]

22. Hickman, M.J.; Winston, F. Heme Levels Switch the Function of Hap1 of Saccharomyces cerevisiae between Transcriptional Activator and Transcriptional Repressor. Mol. Cell. Biol. 2007, 27, 7414-7424. [CrossRef] [PubMed]

23. Wöhl, T.; Klier, H.; Ammer, H.; Lottspeich, F.; Magdolen, V. The HYP2 gene of Saccharomyces cerevisiae is essential for aerobic growth: Characterization of different isoforms of the hypusine-containing protein Hyp2p and analysis of gene disruption mutants. MGG Mol. Gen. Genet. 1993, 241, 305-311. [CrossRef] [PubMed] 
24. Liu, J.; Zhan, X.; Li, M.; Li, G.; Zhang, P.; Xiao, Z.; Shao, M.; Peng, F.; Hu, R.; Chen, Z. Mitochondrial proteomics of nasopharyngeal carcinoma metastasis. BMC Med. Genom. 2012, 5, 62. [CrossRef]

25. Miyake, T.; Pradeep, S.; Wu, S.Y.; Rupaimoole, R.; Zand, B.; Wen, Y.; Gharpure, K.M.; Nagaraja, A.S.; Hu, W.; Cho, M.S.; et al. XPO1/CRM1 inhibition causes antitumor effects by mitochondrial accumulation of eIF5A. Clin. Cancer Res. 2015, 21, 3286-3297. [CrossRef]

26. Pereira, K.D.; Tamborlin, L.; Meneguello, L.; de Proença, A.R.G.; Almeida, I.C.; Lourenço, R.F.; Luchessi, A.D. Alternative Start Codon Connects eIF5A to Mitochondria. J. Cell. Physiol. 2016, 231, 2682-2689. [CrossRef]

27. Weir, B.A.; Yaffe, M.P. Mmd1p, a Novel, Conserved Protein Essential for Normal Mitochondrial Morphology and Distribution in the Fission Yeast Schizosaccharomyces pombe. Mol. Biol. Cell 2004, 15, 1656-1665. [CrossRef]

28. Ma, D.; Zheng, B.; Liu, H.L.; Zhao, Y.B.; Liu, X.; Zhang, X.H.; Li, Q.; Shi, W.B.; Suzuki, T.; Wen, J.K. Klf5 down-regulation induces vascular senescence through eIF5a depletion and mitochondrial fission. PLoS Biol. 2020, 18, e3000808. [CrossRef]

29. Tan, X.; Wang, D.B.; Lu, X.; Wei, H.; Zhu, R.; Zhu, S.S.; Jiang, H.; Yang, Z.J. Doxorubicin induces apoptosis in H9c2 cardiomyocytes: Role of overexpressed Eukaryotic translation initiation factor 5A. Biol. Pharm. Bull. 2010, 33, 1666-1672. [CrossRef]

30. Sun, Z.; Cheng, Z.; Taylor, C.A.; Mcconkey, B.J.; Thompson, J.E. Apoptosis induction by eIF5A1 involves activation of the intrinsic mitochondrial pathway. J. Cell. Physiol. 2010, 223, 798-809. [CrossRef]

31. Melis, N.; Rubera, I.; Cougnon, M.; Giraud, S.; Mograbi, B.; Belaid, A.; Pisani, D.F.; Huber, S.M.; Lacas-Gervais, S.; Fragaki, K.; et al. Targeting eIF5A hypusination prevents anoxic cell death through mitochondrial silencing and improves kidney transplant outcome. J. Am. Soc. Nephrol. 2017, 28, 811-822. [CrossRef] [PubMed]

32. Giraud, S.; Kerforne, T.; Zely, J.; Ameteau, V.; Couturier, P.; Tauc, M.; Hauet, T. The inhibition of eIF5A hypusination by GC7, a preconditioning protocol to prevent brain death-induced renal injuries in a preclinical porcine kidney transplantation model. Am. J. Transplant. 2020. [CrossRef] [PubMed]

33. Bourourou, M.; Gouix, E.; Melis, N.; Friard, J.; Heurteaux, C.; Tauc, M.; Blondeau, N. Inhibition of eIF5A hypusination pathway as a new pharmacological target for stroke therapy. J. Cereb. Blood Flow Metab. 2020. [CrossRef] [PubMed]

34. Puleston, D.J.; Buck, M.D.; Klein Geltink, R.I.; Kyle, R.L.; Caputa, G.; O’Sullivan, D.; Cameron, A.M.; Castoldi, A.; Musa, Y.; Kabat, A.M.; et al. Polyamines and eIF5A Hypusination Modulate Mitochondrial Respiration and Macrophage Activation. Cell Metab. 2019, 30, 1-12. [CrossRef]

35. Schüller, H.J. Transcriptional control of nonfermentative metabolism in the yeast Saccharomyces cerevisiae. Curr. Genet. 2003, 43, 139-160. [CrossRef]

36. Rolland, F.; Winderickx, J.; Thevelein, J.M. Glucose-sensing and -signalling mechanisms in yeast. FEMS Yeast Res. $2002,2,183-201$. [CrossRef]

37. Kayikci, Ö.; Nielsen, J. Glucose repression in Saccharomyces cerevisiae. FEMS Yeast Res. 2015, 15. [CrossRef]

38. Turcotte, B.; Liang, X.B.; Robert, F.; Soontorngun, N. Transcriptional regulation of nonfermentable carbon utilization in budding yeast. FEMS Yeast Res. 2010, 10, 2-13. [CrossRef]

39. Fendt, S.M.; Sauer, U. Transcriptional regulation of respiration in yeast metabolizing differently repressive carbon substrates. BMC Syst. Biol. 2010, 4, 1-12. [CrossRef]

40. Galdieri, L.; Mehrotra, S.; Yu, S.; Vancura, A. Transcriptional regulation in yeast during diauxic shift and stationary phase. Omi. A J. Integr. Biol. 2010, 14, 629-638. [CrossRef]

41. Conrad, M.; Schothorst, J.; Kankipati, H.N.; Van Zeebroeck, G.; Rubio-Texeira, M.; Thevelein, J.M. Nutrient sensing and signaling in the yeast Saccharomyces cerevisiae. FEMS Microbiol. Rev. 2014, 38, 254-299. [CrossRef] [PubMed]

42. Hedbacker, K.; Carlson, M. SNF1/AMPK pathways in yeast. Front. Biosci. 2008, 13, 2408-2420. [CrossRef] [PubMed]

43. Lavoie, H.; Whiteway, M. Increased respiration in the sch $9 \Delta$ mutant is required for increasing chronological life span but not replicative life span. Eukaryot. Cell 2008, 7, 1127-1135. [CrossRef] [PubMed]

44. Sanz, P.; Viana, R.; Garcia-Gimeno, M.A. AMPK in Yeast: The SNF1 (Sucrose Non-fermenting 1) Protein Kinase Complex. EXS 2016, 107, 353-374. [CrossRef] [PubMed]

45. Hughes Hallett, J.E.; Luo, X.; Capaldi, A.P. Snf1/AMPK promotes the formation of Kog1/raptor-bodies to increase the activation threshold of TORC1 in budding yeast. eLife 2015, 4. [CrossRef] [PubMed]

46. Perić, M.; Lovrić, A.; Šarić, A.; Musa, M.; Bou Dib, P.; Rudan, M.; Nikolić, A.; Sobočanec, S.; Mikecin, A.M.; Dennerlein, S.; et al. TORC1-mediated sensing of chaperone activity alters glucose metabolism and extends lifespan. Aging Cell 2017, 16, 994-1005. [CrossRef]

47. Kunkel, J.; Luo, X.; Capaldi, A.P. Integrated TORC1 and PKA signaling control the temporal activation of glucose-induced gene expression in yeast. Nat. Commun. 2019, 10, 3558. [CrossRef]

48. Forsburg, S.L.; Guarente, L. Identification and characterization of HAP4: A third component of the CCAAT-bound HAP2/HAP3 heteromer. Genes Dev. 1989, 3, 1166-1178. [CrossRef]

49. Forsburg, S.L.; Guarente, L. Communication between mitochondria and the nucleus in regulation of cytochrome genes in the yeast Saccharomyces cerevisiae. Annu. Rev. Cell Biol. 1989, 5, 153-180. [CrossRef]

50. Zaman, S.; Lippman, S.I.; Schneper, L.; Slonim, N.; Broach, J.R. Glucose regulates transcription in yeast through a network of signaling pathways. Mol. Syst. Biol. 2009, 5, 245. [CrossRef]

51. DeRisi, J.L.; Iyer, V.R.; Brown, P.O. Exploring the metabolic and genetic control of gene expression on a genomic scale. Science 1997, 278, 680-686. [CrossRef] [PubMed]

52. Zhang, T.; Bu, P.; Zeng, J.; Vancura, A. Increased heme synthesis in yeast induces a metabolic switch from fermentation to respiration even under conditions of glucose repression. J. Biol. Chem. 2017, 292, 16942-16954. [CrossRef] [PubMed] 
53. Valentini, S.R.; Casolari, J.M.; Oliveira, C.C.; Silver, P.A.; McBride, A.E. Genetic interactions of yeast eukaryotic translation initiation factor 5a (eIF5A) reveal connections to poly(A)-binding protein and protein kinase C signaling. Genetics 2002, 160, 393-405. [PubMed]

54. Park, J.H.; Aravind, L.; Wolff, E.C.; Kaevel, J.; Kim, Y.S.; Park, M.H. Molecular cloning, expression, and structural prediction of deoxyhypusine hydroxylase: A HEAT-repeat-containing metalloenzyme. Proc. Natl. Acad. Sci. USA 2006, 103, 51-56. [CrossRef]

55. Smith, A.; Ward, M.P.; Garrett, S. Yeast PKA represses Msn2p/Msn4p-dependent gene expression to regulate growth, stress response and glycogen accumulation. EMBO J. 1998, 17, 3556-3564. [CrossRef]

56. Boy-Marcotte, E.; Perrot, M.; Bussereau, F.; Boucherie, H.; Jacquet, M. Msn2p and Msn4p control a large number of genes induced at the diauxic transition which are repressed by cyclic AMP in Saccharomyces cerevisiae. J. Bacteriol. 1998, 180, 1044-1052. [CrossRef]

57. Pfanzagl, V.; Görner, W.; Radolf, M.; Parich, A.; Schuhmacher, R.; Strauss, J.; Reiter, W.; Schüller, C. A constitutive active allele of the transcription factor Msn2 mimicking low PKA activity dictates metabolic remodeling in yeast. Mol. Biol. Cell 2018, 29, 2848-2862. [CrossRef]

58. Schneider, J.C.; Guarente, L. Regulation of the yeast CYT1 gene encoding cytochrome c1 by HAP1 and HAP2/3/4. Mol. Cell. Biol. 1991, 11, 4934-4942. [CrossRef]

59. Cardenas, M.E.; Cutler, N.S.; Lorenz, M.C.; Di Como, C.J.; Heitman, J. The TOR signaling cascade regulates gene expression in response to nutrients. Genes Dev. 1999, 13, 3271-3279. [CrossRef]

60. Hardwick, J.S.; Kuruvilla, F.G.; Tong, J.K.; Shamji, A.F.; Schreiber, S.L. Rapamycin-modulated transcription defines the subset of nutrient-sensitive signaling pathways directly controlled by the Tor proteins. Proc. Natl. Acad. Sci. USA 1999, 96, 14866-14870. [CrossRef]

61. Proud, C.G. Regulation of mammalian translation factors by nutrients. Eur. J. Biochem. 2002, 268, 5338-5349. [CrossRef] [PubMed]

62. Ramos-Alonso, L.; Romero, A.M.; Martínez-Pastor, M.T.; Puig, S. Iron Regulatory Mechanisms in Saccharomyces cerevisiae. Front. Microbiol. 2020. [CrossRef] [PubMed]

63. Ihrig, J.; Hausmann, A.; Hain, A.; Richter, N.; Hamza, I.; Lill, R.; Mühlenhoff, U. Iron regulation through the back door: Irondependent metabolite levels contribute to transcriptional adaptation to iron deprivation in saccharomyces cerevisiae. Eukaryot. Cell 2010, 9, 460-471. [CrossRef] [PubMed]

64. Warburg, O.; Wind, F.; Negelein, E. The metabolism of tumors in the body. J. Gen. Physiol. 1927, 8, 519-530. [CrossRef]

65. Kroemer, G.; Pouyssegur, J. Tumor Cell Metabolism: Cancer's Achilles' Heel. Cancer Cell 2008, 13, 472-482. [CrossRef]

66. Heiden, M.G.V.; Cantley, L.C.; Thompson, C.B. Understanding the warburg effect: The metabolic requirements of cell proliferation. Science 2009, 324, 1029-1033. [CrossRef]

67. Hukelmann, J.L.; Anderson, K.E.; Sinclair, L.V.; Grzes, K.M.; Murillo, A.B.; Hawkins, P.T.; Stephens, L.R.; Lamond, A.I.; Cantrell, D.A. The cytotoxic T cell proteome and its shaping by the kinase mTOR. Nat. Immunol. 2016, 17, 104-112. [CrossRef]

68. Zanelli, C.F.; Valentini, S.R. Is there a role for eIF5A in translation? Amino Acids 2007, 33, 351-358. [CrossRef]

69. Williams, C.C.; Jan, C.H.; Weissman, J.S. Targeting and plasticity of mitochondrial proteins revealed by proximity-specific ribosome profiling. Science 2014, 346, 748-751. [CrossRef]

70. Zhang, L.; Guarente, L. The yeast activator HAP1-A GAL4 family member-binds DNA in a directly repeated orientation. Genes Dev. 1994, 8, 2110-2119. [CrossRef]

71. Cao, T.T.; Lin, S.H.; Fu, L.; Tang, Z.; Che, C.M.; Zhang, L.Y.; Ming, X.Y.; Liu, T.F.; Tang, X.M.; Tan, B.B.; et al. Eukaryotic translation initiation factor 5A2 promotes metabolic reprogramming in hepatocellular carcinoma cells. Carcinogenesis 2017, 38, 94-104. [CrossRef] [PubMed]

72. San-Millán, I.; Brooks, G.A. Reexamining cancer metabolism: Lactate production for carcinogenesis could be the purpose and explanation of the Warburg Effect. Carcinogenesis 2017, 38, 119-133. [CrossRef] [PubMed]

73. Vasudevan, S.; Peltz, S.W. Regulated ARE-mediated mRNA decay in Saccharomyces cerevisiae. Mol. Cell 2001, 7, 1191-1200. [CrossRef]

74. Puig, S.; Askeland, E.; Thiele, D.J. Coordinated remodeling of cellular metabolism during iron deficiency through targeted mRNA degradation. Cell 2005, 120, 99-110. [CrossRef]

75. Puig, S.; Vergara, S.V.; Thiele, D.J. Cooperation of Two mRNA-Binding Proteins Drives Metabolic Adaptation to Iron Deficiency. Cell Metab. 2008, 7, 555-564. [CrossRef]

76. Ramos-Alonso, L.; Romero, A.M.; Soler, M.À.; Perea-García, A.; Alepuz, P.; Puig, S.; Martínez-Pastor, M.T. Yeast Cth2 protein represses the translation of ARE-containing mRNAs in response to iron deficiency. PLoS Genet. 2018, 14, e1007476. [CrossRef]

77. Longtine, M.S.; McKenzie, A.; Demarini, D.J.; Shah, N.G.; Wach, A.; Brachat, A.; Philippsen, P.; Pringle, J.R. Additional modules for versatile and economical PCR-based gene deletion and modification in Saccharomyces cerevisiae. Yeast 1998, 14, 953-961. [CrossRef]

78. Gietz, D.; Jean, A.S.; Woods, R.A.; Schiestl, R.H. Improved method for high efficiency transformation of intact yeast cells. Nucleic Acids Res. 1992, 20, 1425. [CrossRef]

79. Zuzuarregui, A.; Li, T.; Friedmann, C.; Ammerer, G.; Alepuz, P. Msb2 is a Ste11 membrane concentrator required for full activation of the HOG pathway. Biochim. Biophys. Acta Gene Regul. Mech. 2015, 1849, 722-730. [CrossRef]

80. Garre, E.; Romero-Santacreu, L.; Barneo-Muñoz, M.; Miguel, A.; Pérez-Ortín, J.E.; Alepuz, P. Nonsense-Mediated mRNA Decay Controls the Changes in Yeast Ribosomal Protein Pre-mRNAs Levels upon Osmotic Stress. PLoS ONE 2013, 8. [CrossRef] 